\title{
Surface Corrosion Resistance in Turning of Titanium Alloy
}

\author{
Rui Zhang, ${ }^{1}$ Xing Ai, ${ }^{1}$ Yi Wan, ${ }^{1}$ Zhanqiang Liu,, ${ }^{1}$ Dong Zhang, ${ }^{2}$ and Sheng Feng ${ }^{1}$ \\ ${ }^{1}$ Key Laboratory of High Efficiency and Clean Manufacturing, School of Mechanical Engineering, Shandong University, \\ Shandong 250061, China \\ ${ }^{2}$ Qilu Hospital, Shandong University, Shandong 250002, China
}

Correspondence should be addressed to Yi Wan; wanyi@sdu.edu.cn

Received 17 June 2015; Accepted 18 August 2015

Academic Editor: Michael J. Schütze

Copyright (C) 2015 Rui Zhang et al. This is an open access article distributed under the Creative Commons Attribution License, which permits unrestricted use, distribution, and reproduction in any medium, provided the original work is properly cited.

\begin{abstract}
This work addresses the issues associated with implant surface modification. We propose a method to form the oxide film on implant surfaces by dry turning to generate heat and injecting oxygen-rich gas at the turning-tool flank. The morphology, roughness, composition, and thickness of the oxide films in an oxygen-rich atmosphere were characterized using scanning electron microscopy, optical profiling, and Auger electron spectroscopy. Electrochemical methods were used to study the corrosion resistance of the modified surfaces. The corrosion resistance trends, analyzed relative to the oxide film thickness, indicate that the oxide film thickness is the major factor affecting the corrosion resistance of titanium alloys in a simulated body fluid (SBF). Turning in an oxygen-rich atmosphere can form a thick oxide film on the implant surface. The thickness of surface oxide films processed at an oxygen concentration of $80 \%$ was improved to 4.6 times that of films processed at an oxygen concentration of $21 \%$; the free corrosion potential shifted positively by $0.357 \mathrm{~V}$, which significantly improved the corrosion resistance of titanium alloys in the SBF. Therefore, the proposed method may (partially) replace the subsequent surface oxidation. This method is significant for biomedical development because it shortens the process flow, improves the efficiency, and lowers the cost.
\end{abstract}

\section{Introduction}

Titanium and its alloys are easily passivated metals. The passivation film on the surface is very stable and has excellent corrosion resistance and biocompatibility in oxidizing, neutral, and weakly reducing media [1]. A blackening phenomenon was reported for tissues surrounding titanium implants in animal experiments and clinical applications $[2,3]$. This effect is attributed to the corrosive dissolution of titanium and its alloys, which were enriched in the surrounding tissue and degenerated cells. Corrosion generates (unwanted) products that enter the body and may cause severe physical harm (e.g., tissue poisoning or cell distortion). Moreover, it causes defects such as loosening and early fracture of implants. Therefore, the issues regarding the corrosion of titanium alloys have become a focus for the academic community [46].

To improve their corrosion resistance and biocompatibility, titanium alloys must undergo surface oxidation before implantation. For example, the sol-gel method is used to generate a titanium dioxide surface coating rich in $\mathrm{Ti}-\mathrm{OH}$ groups, which may induce the nucleation of apatite and improve the implant-bone combination $[7,8]$. Liu et al. [9] used a sol-gel method to fabricate uniform and dense titanium dioxide ( $205 \mathrm{~nm}$ thick) on the surface of a NiTi alloy. They studied the corrosion resistance of the film in Tyrode's solution and concluded that a titanium dioxide thin film can effectively improve the corrosion resistance of the NiTi alloy. Poon et al. [10] used plasma-immersion ion implantation (PIII) to implant oxygen ions into the NiTi alloy and formed a layer of titanium dioxide on the surface, which significantly improved the corrosion resistance and reduced the amount of $\mathrm{Ni}$ ions that were released into body fluids. Cigada et al. [11] fabricated an oxide film by anodizing TC4 inside an $\mathrm{H}_{3} \mathrm{PO}_{4}$ bath. This film significantly reduced the release of metal ions (e.g., titanium, aluminum, and vanadium) from the titanium base due to dissolution and improved the corrosion resistance of the titanium alloy in the simulated body fluid (SBF). Nie et al. [12] employed a hybrid processing method combining microarc oxidation and electrophoretic deposition to deposit a layer of hydroxyapatite on the surface of an oxide film. They used an electrochemical corrosion 

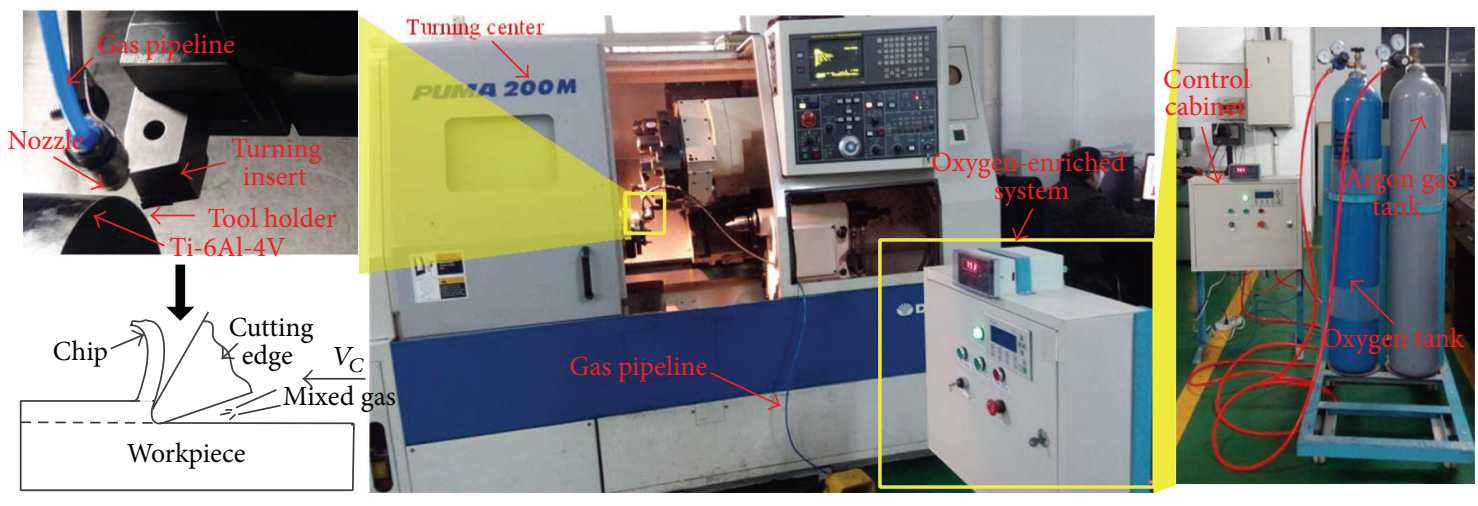

FIgURE 1: Turning-experiment apparatus in an oxygen-rich atmosphere.

method to test the corrosion resistance of the coating in buffered physiological solutions. Their results showed that the titanium dioxide thin film effectively improved the corrosion resistance of the titanium alloys. All of these surfaceprocessing methods maintained the excellent properties of titanium and its alloys (e.g., low modulus, high fatigue strength, and good formability) and improved the materials' corrosion resistance and effectiveness in clinical applications. However, the aforementioned methods are applied after the final formation of the parts. The process is lengthy, with a low efficiency and high costs, and the processing apparatus is highly complex.

Herein, we propose a method involving dry turning while injecting oxygen-rich gas at the flank of the turning-tool to form a layer of oxide film on the titanium components. The oxygen-rich atmosphere increases the partial pressure of oxygen in the oxidizing environment. Additionally, the heat generated by the turning increases the temperature and the rate of the oxidation. Electrochemical methods were used to measure the corrosion resistance of the processed surface in Hank's SBF. An analysis of the corrosion mechanism of the titanium alloys in the SBF was conducted.

\section{Materials and Methods}

2.1. Preparation of Samples. The selected test material was a biological-grade titanium alloy Ti-6Al-4V that is commonly used in medical practices. The turning was conducted in an oxygen-rich atmosphere at PUMA200M Turning Center (Daewoo, South Korea). The oxygen-rich atmosphere was created with an automatic gas-mixing system that was designed and developed in our laboratory. The setup of the experimental equipment is shown in Figure 1. The gas-mixing system automatically mixes argon and oxygen, and argon acts as a protective gas. The output flow, pressure, and oxygen concentration of the mixed gas are adjusted according to the working requirements in the field. The output pressure of the mixed gas in the experiment was $0.3 \mathrm{MPa}$ at $0.3 \mathrm{~L} / \mathrm{min}$. The materials were divided into three groups, as shown in Table 1. The cutting parameters are presented in our published work [13]. The samples were cut with dimensions of $10 \mathrm{~mm} \times 8 \mathrm{~mm}$ $\times 5 \mathrm{~mm}$. They were ultrasonically cleaned in acetone and ultrapure water (Millipore) for $10 \mathrm{~min}$ and dried.
TABLE 1: Cutting parameters.

\begin{tabular}{lcccc}
\hline Number & $\begin{array}{c}V \\
(\mathrm{~m} / \mathrm{min})\end{array}$ & $\begin{array}{c}a_{p} \\
(\mathrm{~mm})\end{array}$ & $\begin{array}{c}f \\
(\mathrm{~mm} / \mathrm{r})\end{array}$ & $\begin{array}{c}\text { Oxygen concentration } \\
(\%)\end{array}$ \\
\hline Group I & 500 & 0.1 & 0.01 & 21 (natural condition) \\
Group II & 500 & 0.1 & 0.01 & 55 \\
Group III & 500 & 0.1 & 0.01 & 80 \\
\hline
\end{tabular}

2.2. Sample Characterization. The surface morphology of the samples was observed and characterized using (1) a fieldemission scanning electron microscope that was equipped with energy dispersive spectroscopy (SUPRA 55 SAPPHIRE, Carl Zeiss, Germany) and had an acceleration voltage of $10 \mathrm{kV}$ and (2) a three-dimensional microscope with a large depth of field (VHX-600E, Keyence, Japan). The surface roughness was measured using an optical profiler (Veeco NT9300, Veeco, USA). The thickness of the oxide layer and the surface elemental compositions were measured by Auger Electron Spectroscopy (AES) using a Scanning Auger Nanoprobe (PHI-700 AES, ULVAC-PHI, Japan) equipped with $5-\mathrm{keV}$ Ar ions for etching the rear part. The standard sample was thermal $\mathrm{SiO}_{2}$. The energy resolution is $1 \%$, and the incident angle is $30^{\circ}$. The vacuum of the analyzing chamber was greater than $3.9 \times 10^{-9}$ Torr.

2.3. Electrochemical Experiment Method. An electrochemical workstation with a three-electrode system (CHI660D, Chen Hua, Shanghai, China) was chosen for inducing the constantpotential corrosion. The reference electrode was a saturated calomel electrode produced by Tianjin Aida Hengsheng Technology Co., Ltd. The comparison electrode was a shiny square platinum plate. The medium for the corrosion was Hank's SBF. To ensure the validity of the measurement, the surfaces of the sample, except for the turning surface, were sealed before the test with organic glue. The sample was connected to the test instrument by a conductive wire. The exposure area of the sample (i.e., the working electrode) was $0.4 \mathrm{~cm}^{2}$. The sample was stabilized for $30 \mathrm{~min}$ under the opencircuit potential. The potential was scanned in the range of $-800-1000 \mathrm{mV}$ at rate of $1 \mathrm{mV} / \mathrm{s}$. 

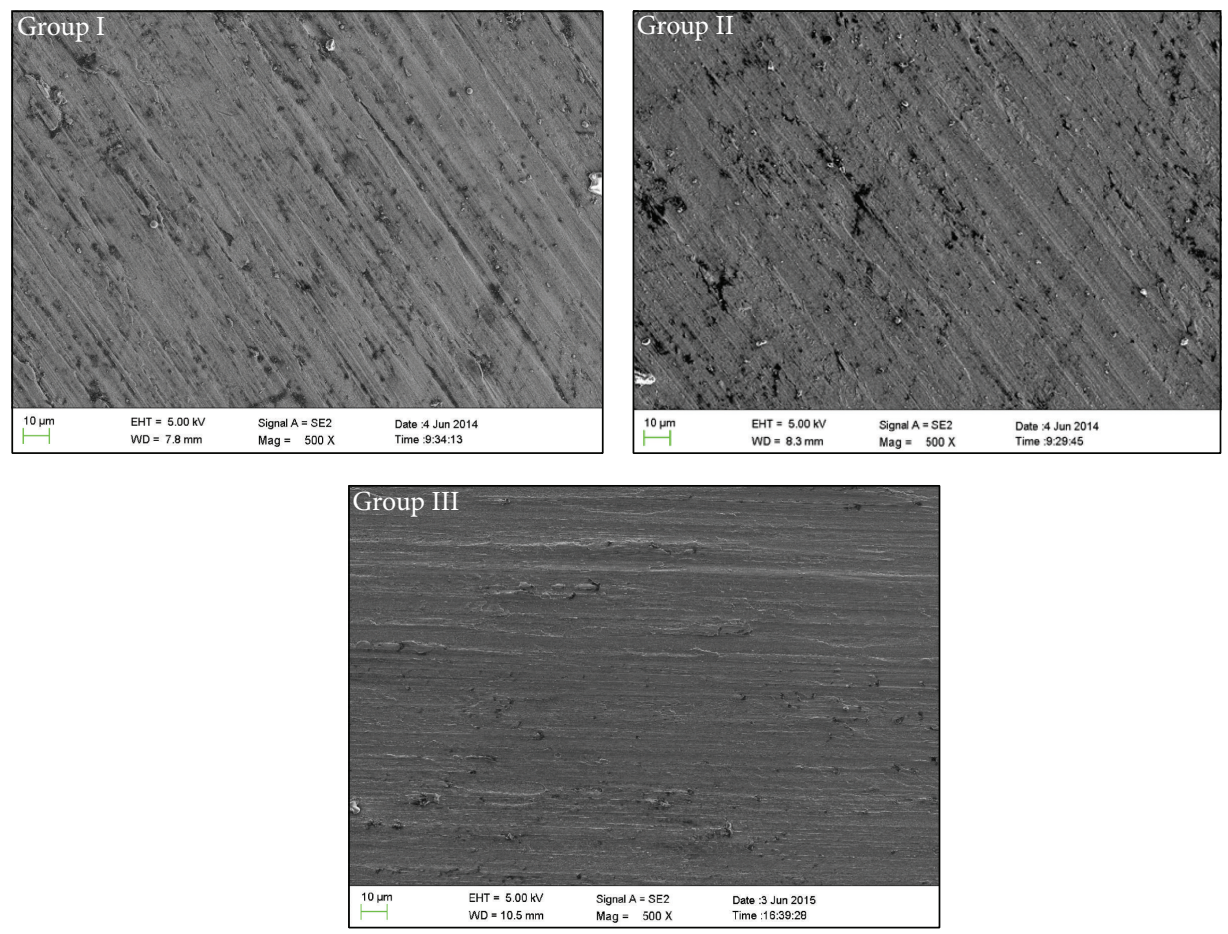

FIGURE 2: Images of surface morphology during turning under different gas conditions.

\section{Results and Discussions}

3.1. Surface Morphology and Surface Roughness. The surface morphology and roughness are important factors affecting the corrosion resistance of a surface. For the same cutting parameters with different oxygen-rich atmospheres, there were always clear passing marks of the cutting tool on the turning surfaces, and the surface morphologies were very similar (Figure 2$)$. The surface roughness $\left(R_{a}\right)$ was measured using the optical profiler with a resolution of $355 \pm 31 \mathrm{~nm}$, $367 \pm 25 \mathrm{~nm}$, and $351 \pm 17 \mathrm{~nm}$ for the surfaces of the samples in Groups I, II, and III, respectively. The surface roughness was at the same level for all three groups. Therefore, the surface morphology and roughness did not significantly affect the corrosion resistance among the three groups of samples.

\subsection{Surface Composition and Oxide Film Thickness}

3.2.1. Surface Composition. The relative elemental concentrations of the sample surfaces are shown in Figure 3. The concentration was relatively similar among all of the samples. Strong signals from titanium, oxygen, and carbon dominate the spectroscopy results. The measurements indicate that the oxides on the titanium surface due to turning in an oxygenrich atmosphere were clean. There was only one extremely thin-layer carbon contamination on the surface. Oxygen-rich gas was injected at the flank of the cutting tool during the processing of the titanium alloy. The freshly exposed surface resulting from the processing was completely surrounded by oxygen-rich gas, which prevented the reaction of the titanium with other gases such as nitrogen and hydrogen.
This improved the purity of the oxide film on the surface of the titanium alloy. When the sample was exposed to air, the surface absorbed a large amount of carbon. As the analysis time is extended, the accumulation of carbon on the sample surface increases, which contributes to a relatively strong signal for carbon in the AES analysis [14].

3.2.2. Oxide Film Thickness. The oxide film on the surface of titanium alloy has a good corrosion resistance. Figure 4 shows the evolving curves for the relative concentrations of titanium and oxygen in the processed samples with respect to the sputtering time. The oxide thickness was calculated as the product of the sputtering rate and the sputtering time when the peak amplitude of oxygen decreased to $50 \%$. The sputtering rate was $38 \mathrm{~nm} / \mathrm{s}$. According to the calculations of the oxide film thickness shown in Figure 5, the oxide film thicknesses on the sample surface for oxygen concentrations of $80 \%$ and $55 \%$ were $69 \mathrm{~nm}$ and $52 \mathrm{~nm}$, respectively. The films were 4.6 and 3.4 times thicker, respectively, than the surface oxide film $(15 \mathrm{~nm})$ processed at an oxygen concentration of $21 \%$. Therefore, injecting oxygen-rich gas at the flank of the cutting tool during the turning accelerated the oxidation of the titanium alloys and significantly increased the thickness of the surface oxide film. This allowed the freshly processed surface to be instantaneously surrounded by an oxygen-rich atmosphere. The freshly exposed titanium surface reacted violently with the oxygen-containing mixed gas when they came into contact. The intensity of this reaction depends on the oxygen concentration and the pressure of the mixed gas. A higher mixed-gas pressure and oxygen concentration yield a more violent oxidation reaction. Hence, thick surface 

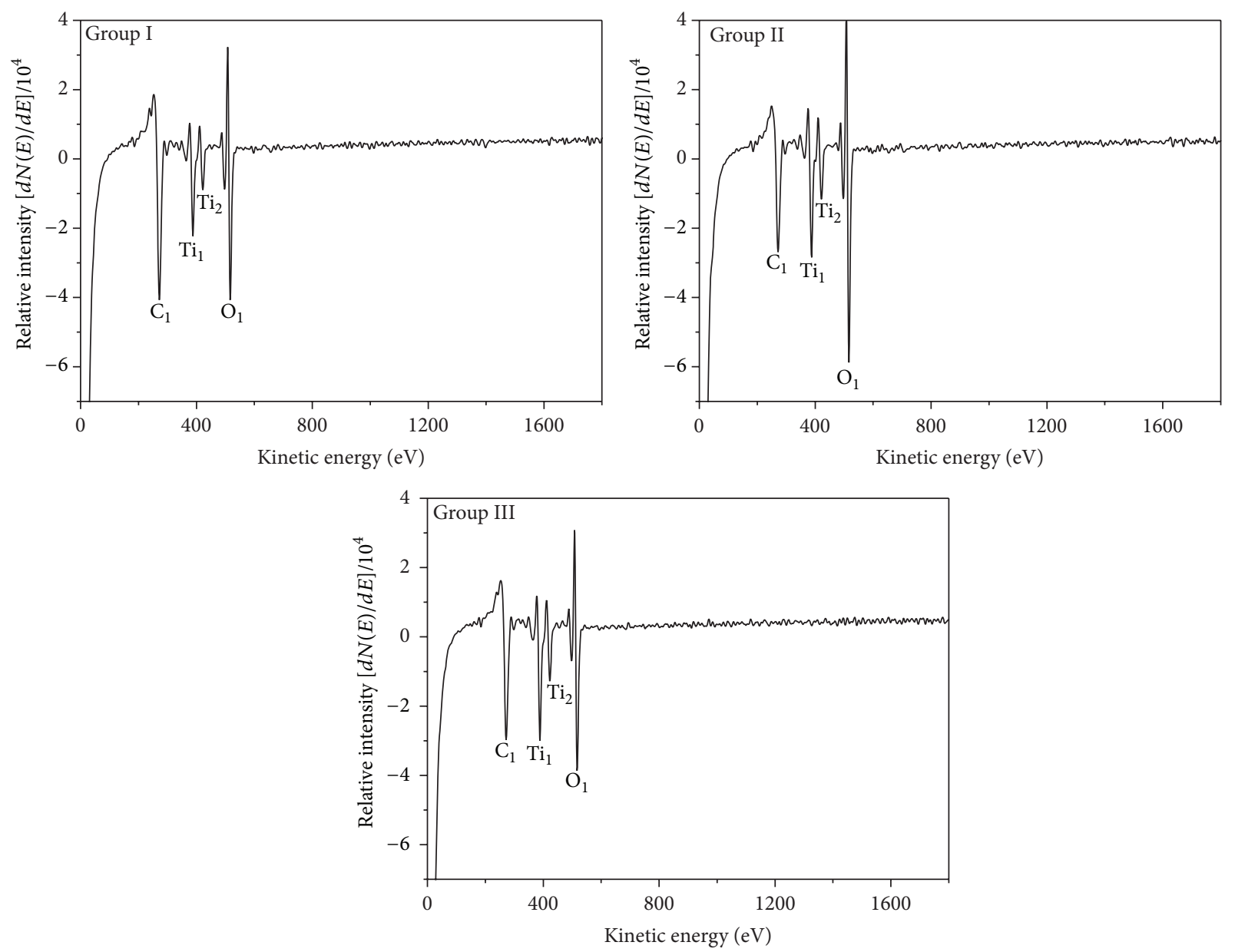

FIGURE 3: AES spectroscopy to determine the relative concentrations of elements on the sample surface.

oxide films were obtained by turning parts in an oxygen-rich atmosphere to increase the oxidation rate.

\subsection{Electrochemical Corrosion Analysis}

3.3.1. Surface Corrosion Analysis. There were no obvious changes in the surface morphology of the samples after the electrochemical corrosion measurements in Hank's SBF $(\mathrm{pH}=7.4)$. No localized corrosion such as pitting was observed (Figure 6). The passivation state of the surface oxide film was not destroyed by the chloride when the titanium alloy remained in a weak alkaline SBF containing a large amount of $\mathrm{Cl}^{-}$. The reasons for this are discussed below. On one hand, the surface oxide film that formed during turning was uniform and dense. Regions with weak links between oxygen and metal were not easily formed. During the electrochemical corrosion, the anodic polarity was similar throughout the titanium alloy surface. Regions with stronger and weaker polarities did not develop easily; thus, the surface corrosion had a high uniformity. On the other hand, chloride is not better than oxygen with regard to its bonding strength or affinity to titanium. It is difficult for chloride to replace oxygen in the oxide film. Equations (1) and (2) are the atomic binding energy $(\mathrm{ABE})$ equation and the environmentally sensitive embedding energy (ESEE) equation for doping elements, respectively;

$$
\begin{aligned}
E_{b} & =E-\sum E_{1} \\
E_{\mathrm{ESE}} & =E_{b}^{i}-E_{b}^{\mathrm{cl}} .
\end{aligned}
$$

Here, $E_{b}$ is the $\mathrm{ABE}$; $E$ is the structural energy; $E_{1}$ is the free energy of the isolated atoms; $E_{\mathrm{ESE}}$ is the ESEE; $E_{b}^{i}$ is the ABE when there are dopant atoms; and $E_{b}^{\mathrm{cl}}$ is the $\mathrm{ABE}$, excluding the dopant atoms.

The $\mathrm{ABE}$ reflects the strength of the association between the atoms. A low $\mathrm{ABE}$ indicates a strong association between the atoms and a stable atomic cluster. A low ESEE indicates a small influence of the dopant atoms on the environment. A stable atom causes a large inclination for the dopant atoms to be segregated at its location, along with a large affinity of the dopant atoms to the base material. The $\mathrm{ABE}$ for titanium and oxygen is smaller than that for titanium and chlorine [15]. Oxygen binds with titanium more easily than chlorine. The ESEE on a surface generated by chlorine is higher than that 


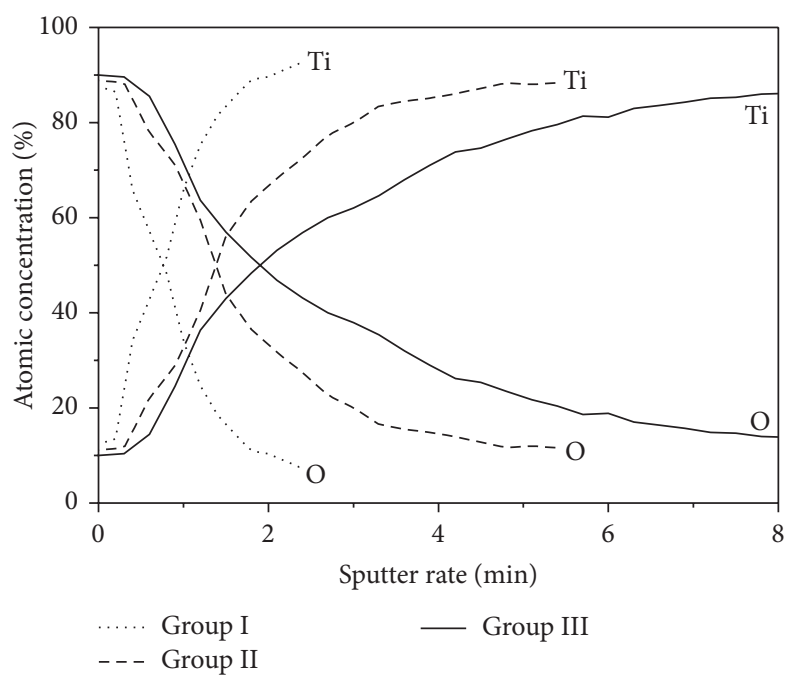

FIgURE 4: AES elemental deep-analysis spectroscopy.

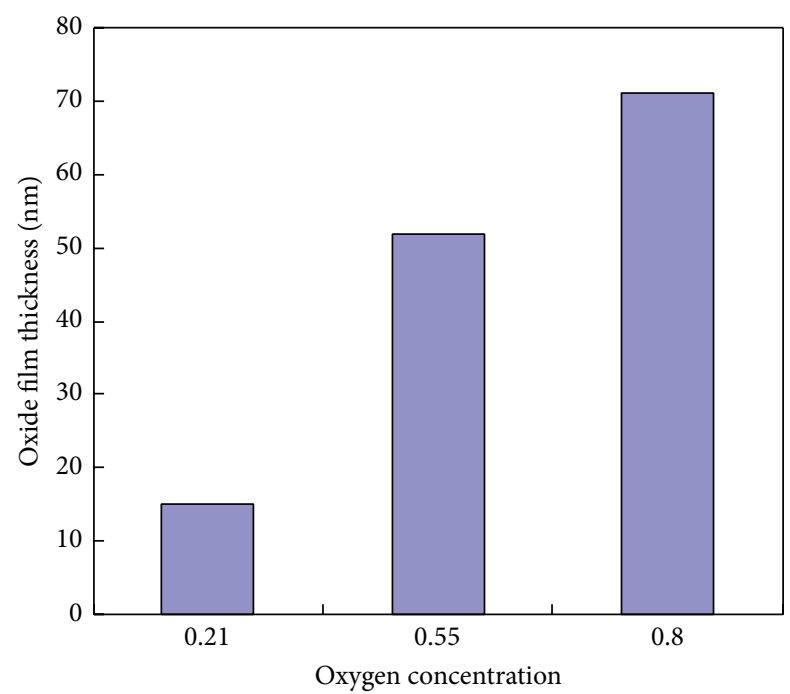

Figure 5: Surface oxide film thickness with respect to oxygen concentration during processing.

on a surface generated by oxygen. The stability of chlorine in titanium is worse than that of oxygen. There are $d$-orbital vacancies for electrons and unpaired electrons in a titanium atom, and oxygen atoms have unpaired electrons as well, which may form covalent bonds or complimentary ionic bonds with paired electrons. Therefore, neither the stability of chlorine in titanium nor affinity of chlorine to titanium matches those of oxygen. Chlorine cannot easily replace the oxygen in titanium oxide, which makes the titanium oxide film very stable. The film retains its passivation state in chloride-containing solutions. When there is a uniform and dense oxide film on the surface of the titanium alloy, it is very difficult for localized corrosion such as pitting to occur.

3.3.2. Polarization Curves. Polarization curves, which are used to report the corrosion properties of a metal, are commonly used in research on electrochemical corrosion. A larger free corrosion potential and smaller passivation current yield a better corrosion resistance. As shown in Figure 7, the free corrosion potentials for Groups II and III are -0.006 and $0.187 \mathrm{~V}$, respectively, exhibiting improvements of 0.164 and $0.357 \mathrm{~V}$, respectively, compared with Group I $(-0.170 \mathrm{~V})$. The polarization curves of the samples apparently shift toward the upper-left direction (in the figure) as the oxygen concentration increases. The associated passivation currents decrease noticeably and are far smaller than that of the sample that was turned under natural conditions.

The surface morphology, roughness, and thickness of the surface oxide film are the major factors affecting the corrosion resistance of titanium alloys in the SBF. All three groups of samples have a similar surface morphology and surface roughness. These two factors do not cause significant changes to the surface corrosion resistance. Therefore, the oxide film thickness is the major factor causing the differences in the corrosion rates. The corrosion results indicate that a thicker oxide film yields a better corrosion resistance of the titanium alloys in the SBF. The reaction mechanisms of the titanium alloys in the SBF are as follows.

There is $\mathrm{Ti}^{4+}$ at the interface between the titanium and titanium dioxide in the titanium alloys:

$$
\mathrm{Ti} \Longleftrightarrow \mathrm{Ti}^{4+}+4 e
$$

The decomposition rate of titanium is far larger than the synthesis rate because titanium is an active metal. Titanium atoms enter the oxide from the metal lattices, and there are excessive metal ions and electrons for the equivalent amount (of titanium-ion materials) inside the oxide (Figure 8). The excessive metal ions and electrons move in the lattices and make the oxide conductive, allowing the metal ions to diffuse toward the outside of the oxide. Hence, the transportation of the charges through the anodic passivation film is largely facilitated by the movements of the ions:

$$
\mathrm{Ti} \Longleftrightarrow \mathrm{Ti}^{4+}+4 e^{-}
$$

When $\mathrm{Ti}^{4+}$ diffuses into the contacting interface between the oxide film and the SBF, large amounts of chloride in the SBF combine with the ions from the passivation film to form soluble alkali chloride. This occurs because chloride has a strong oxidizing capacity and can be preferentially absorbed onto the passivation film. The formed alkali chloride enters the SBF. The reaction mechanism is given as follows [16]:

$$
\begin{aligned}
& \mathrm{Ti}_{\mathrm{ox}}^{4+}+\mathrm{Cl}_{\mathrm{aq}}^{-}+\mathrm{H}_{2} \mathrm{O} \Longleftrightarrow[\mathrm{Ti} \cdot \mathrm{Cl} \cdot \mathrm{OH}]_{\mathrm{ox}}^{2+}+\mathrm{H}_{\mathrm{aq}}^{+}, \\
& {[\mathrm{Ti} \cdot \mathrm{Cl} \cdot \mathrm{OH}]_{\mathrm{ox}}^{2+} } \longrightarrow[\mathrm{Ti} \cdot \mathrm{Cl} \cdot \mathrm{OH}]_{\mathrm{aq}}^{2+}, \\
& {[\mathrm{Ti} \cdot \mathrm{Cl} \cdot \mathrm{OH}]_{\mathrm{aq}}^{2+}+2 \mathrm{H}_{2} \mathrm{O}=\left[\mathrm{Ti}(\mathrm{OH})_{3}\right] \mathrm{Cl}+2 \mathrm{H}_{\mathrm{aq}}^{+} }
\end{aligned}
$$

Titanium dioxide is an n-type semiconductor. Therefore, increasing the thickness and density of the titanium dioxide film increases the electrical resistance of the oxide film. The significantly decreased conductivity of the titanium oxide film makes it difficult for $\mathrm{Ti}^{4+}$ to diffuse out of the oxide film. 

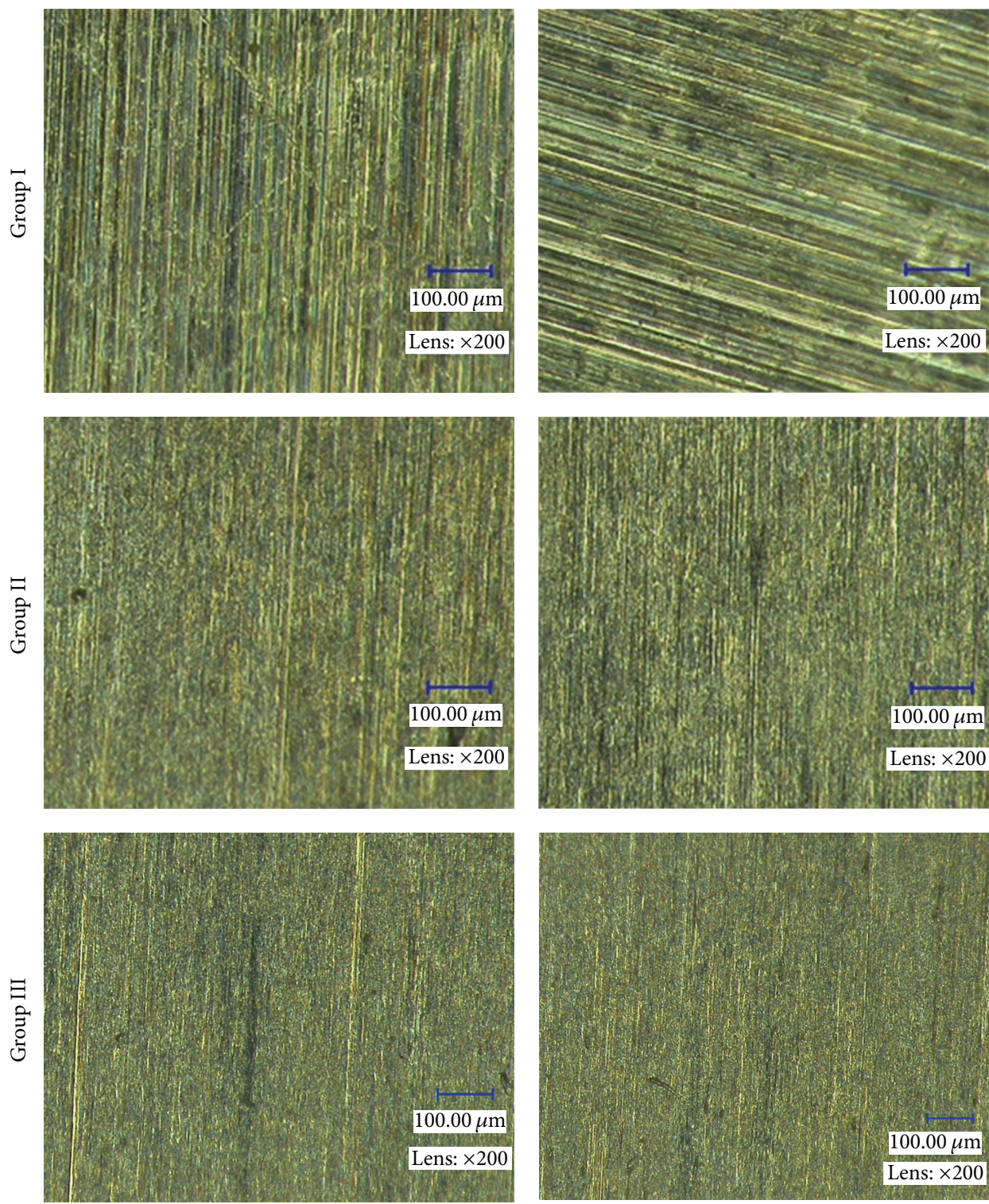

(a) Before corrosion

(b) After corrosion

FIGURE 6: Images of turning sample under different gas conditions before and after surface corrosion.

Hence, an increased thickness of the titanium dioxide film greatly decreases the dissolution speed of the titanium ions, which reduces the reactant amounts in (5), as the reaction limits for (5), (6), and (7) are reduced. This process reduces the amount of titanium ions that enter the SBF and enhances the corrosion resistance of the titanium alloy in the SBF.

\section{Conclusions}

(1) Turning in an oxygen-rich atmosphere significantly increases the oxide film thickness on the surface of the processed part. The oxide films on the surfaces of parts processed with turning at oxygen concentrations of $80 \%$ and $55 \%$ in oxygen-rich gas were 4.6 and 3.4 times thicker, respectively, than films on parts processed under natural conditions.
The oxygen-rich atmosphere prevented the titanium from reacting with other gases such as nitrogen and hydrogen, increasing the purity of the oxide film on the surface of the titanium alloy.

(2) It is difficult for localized corrosion such as pitting to occur on the surface of the parts processed by turning in an oxygen-rich atmosphere in Hank's SBF. The properties of chlorine, both its affinity to titanium and stability with titanium, are inferior to those of oxygen. Chlorine cannot easily replace oxygen in titanium oxide, which makes the surface oxide film very stable. The oxide film maintains its passivation state even with large amounts of chloride in the SBF.

(3) Turning in an oxygen-rich atmosphere significantly enhances the corrosion resistance of the surface of the processed part. The increased thickness of the oxide film increases 


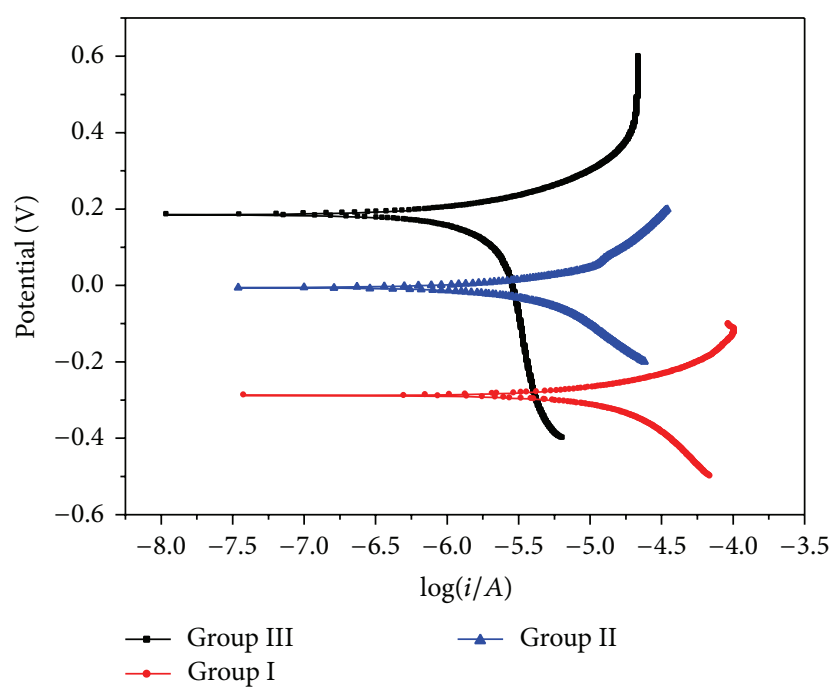

FIgURE 7: Polarization curves of samples from Groups I, II, and III at a pH of $7.4 \pm 0.5$, obtained using Hank's solution to simulate a bodily fluid.

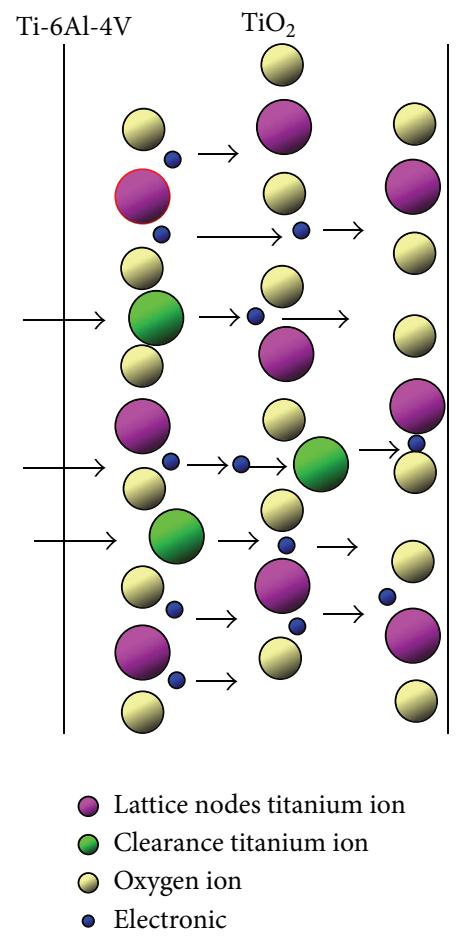

FIGURE 8: Schematic of the diffusion of the excessive titanium ions and electrons in the $\mathrm{TiO}_{2}$ lattice.

its electrical resistance. The decreased conductivity reduces the dissolution speed of the titanium ions and enhances the corrosion resistance of the titanium alloy.

\section{Conflict of Interests}

The authors declare that there is no conflict of interests regarding the publication of this paper.

\section{Acknowledgments}

This project was funded by National Natural Science Foundation of China (51175306, 51425503), Tai Shan Scholar Foundation, and Fundamental Research Funds for the Central Universities (2014JC020).

\section{References}

[1] P. Tengvall and I. Lundström, "Physico-chemical considerations of titanium as a biomaterial," Clinical Materials, vol. 9, no. 2, pp. 115-134, 1992.

[2] I. H. Moon, K. N. Park, H. K. Kim, and S. Lee, "Utility and safety of commercially available injection laryngoplasty materials in a rabbit model," Journal of Voice, vol. 29, no. 1, pp. 125-128, 2015.

[3] D. P. Perl and A. R. Brody, "Alzheimer's disease: X-ray spectrometric evidence of aluminum accumulation in neurofibrillary tangle-bearing neurons," Science, vol. 208, no. 4441, pp. 297299, 1980.

[4] T. Akahori and M. Niinomi, "Fracture characteristics of fatigued Ti-6Al-4V ELI as an implant material," Materials Science and Engineering A, vol. 243, no. 1-2, pp. 237-243, 1998.

[5] L.-H. Li, Y.-M. Kong, H.-W. Kim et al., "Improved biological performance of $\mathrm{Ti}$ implants due to surface modification by micro-arc oxidation," Biomaterials, vol. 25, no. 14, pp. 28672875, 2004.

[6] X. Liu, P. K. Chu, and C. Ding, "Surface modification of titanium, titanium alloys, and related materials for biomedical applications," Materials Science and Engineering, vol. 47, no. 3-4, pp. 49-121, 2004.

[7] M. C. Advincula, F. G. Rahemtulla, R. C. Advincula, E. T. Ada, J. E. Lemons, and S. L. Bellis, "Osteoblast adhesion and matrix mineralization on sol-gel-derived titanium oxide," Biomaterials, vol. 27, no. 10, pp. 2201-2212, 2006.

[8] G. He, J. Hu, S. C. Wei, J. H. Li, X. H. Liang, and E. Luo, "Surface modification of titanium by nano- $\mathrm{TiO}_{2} / \mathrm{HA}$ bioceramic coating," Applied Surface Science, vol. 255, no. 2, pp. 442-445, 2008.

[9] J.-X. Liu, D.-Z. Yang, F. Shi, and Y.-J. Cai, "Sol-gel deposited $\mathrm{TiO}_{2}$ film on NiTi surgical alloy for biocompatibility improvement," Thin Solid Films, vol. 429, no. 1-2, pp. 225-230, 2003.

[10] R. W. Y. Poon, J. P. Y. Ho, X. Liu et al., "Anti-corrosion performance of oxidized and oxygen plasma-implanted NiTi alloys," Materials Science and Engineering A, vol. 390, no. 1-2, pp. 444-451, 2005.

[11] A. Cigada, M. Cabrini, and P. Pedeferri, "Increasing of the corrosion resistance of the Ti6Al4V alloy by high thickness anodic oxidation," Journal of Materials Science: Materials in Medicine, vol. 3, no. 6, pp. 408-412, 1992.

[12] X. Nie, A. Leyland, and A. Matthews, "Deposition of layered bioceramic hydroxyapatite/ $\mathrm{TiO}_{2}$ coatings on titanium alloys using a hybrid technique of micro-arc oxidation and electrophoresis," Surface and Coatings Technology, vol. 125, no. 1-3, pp. 407-414, 2000.

[13] R. Zhang, Y. Wan, X. Ai, B. Men, D. Zhang, and C. Liu, "Titanium oxide film generation on machined implant surface," Sichuan Daxue Xuebao (Gongcheng Kexue Ban), vol. 47, no. 2, pp. 214-218, 2015.

[14] H. J. Mathieu, J. B. Mathieu, D. E. McClure, and D. Landolt, "Beam effects in Auger electron spectroscopy analysis of titanium oxide films," Journal of Vacuum Science and Technology, vol. 14, no. 4, pp. 1023-1028, 1977. 
[15] G. L. Liu, "Electronic theoretical study on the corrosion and passivation mechanism of Ti metal," Acta Physica Sinica, vol. 57, no. 7, pp. 4441-4445, 2008.

[16] X. Zhang, S. Yu, Z. He, and Y. Liu, "Electrochemcal corrosion of new dental ti alloys in an artifical body fluid," Corrosion Science and Protection Technology, vol. 15, no. 5, pp. 249-253, 2003. 

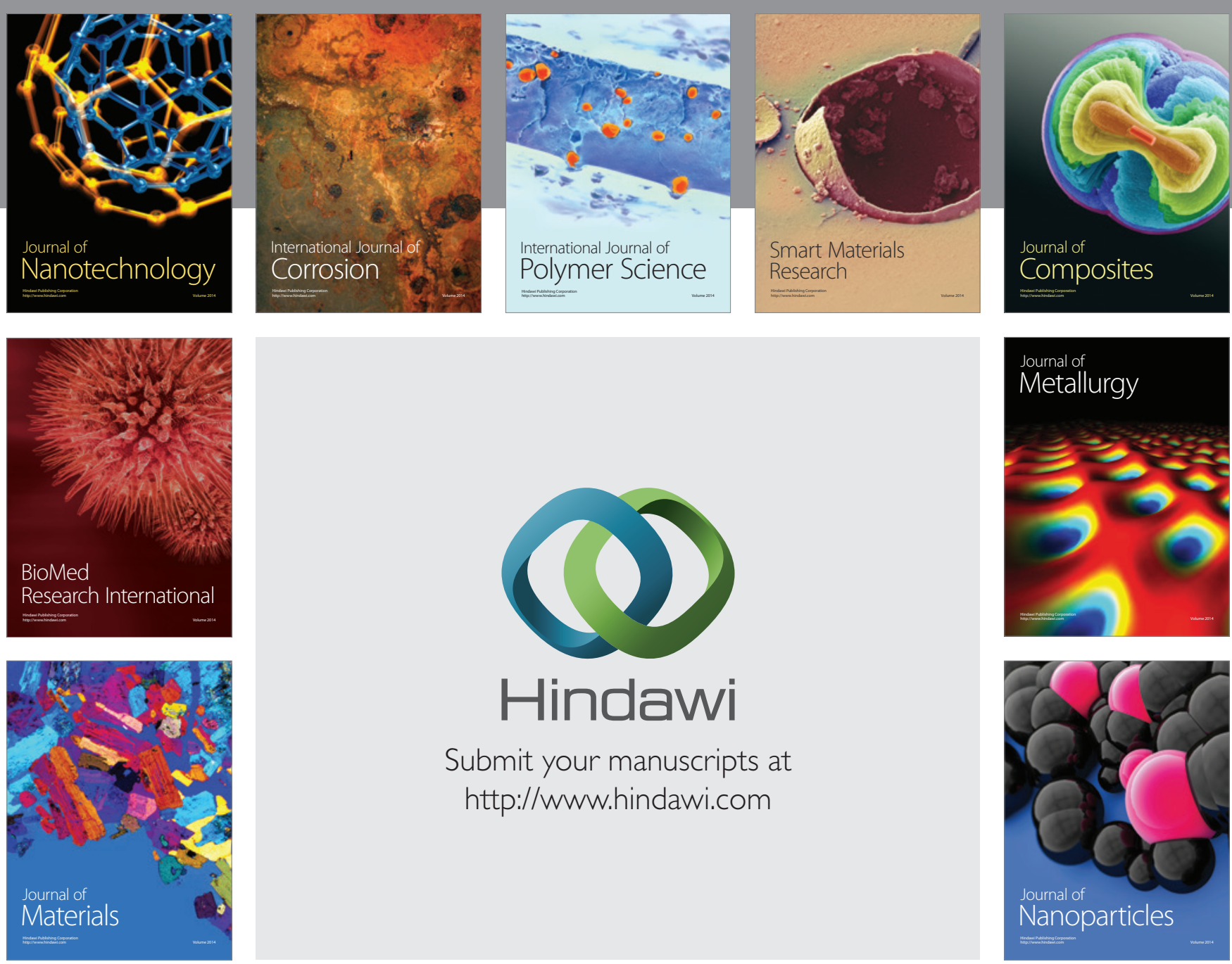

Submit your manuscripts at http://www.hindawi.com
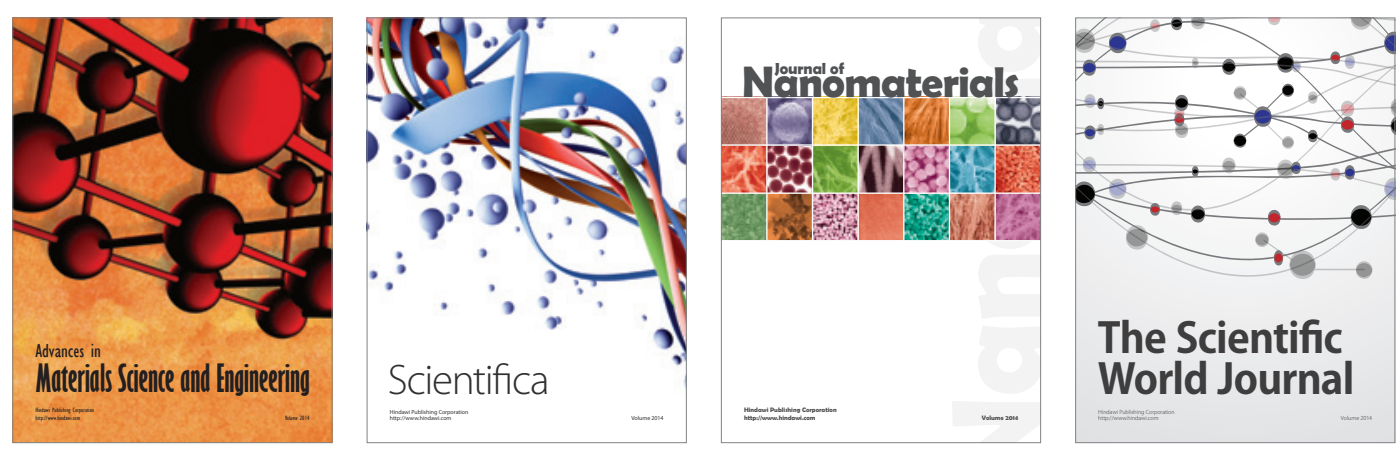

\section{The Scientific World Journal}
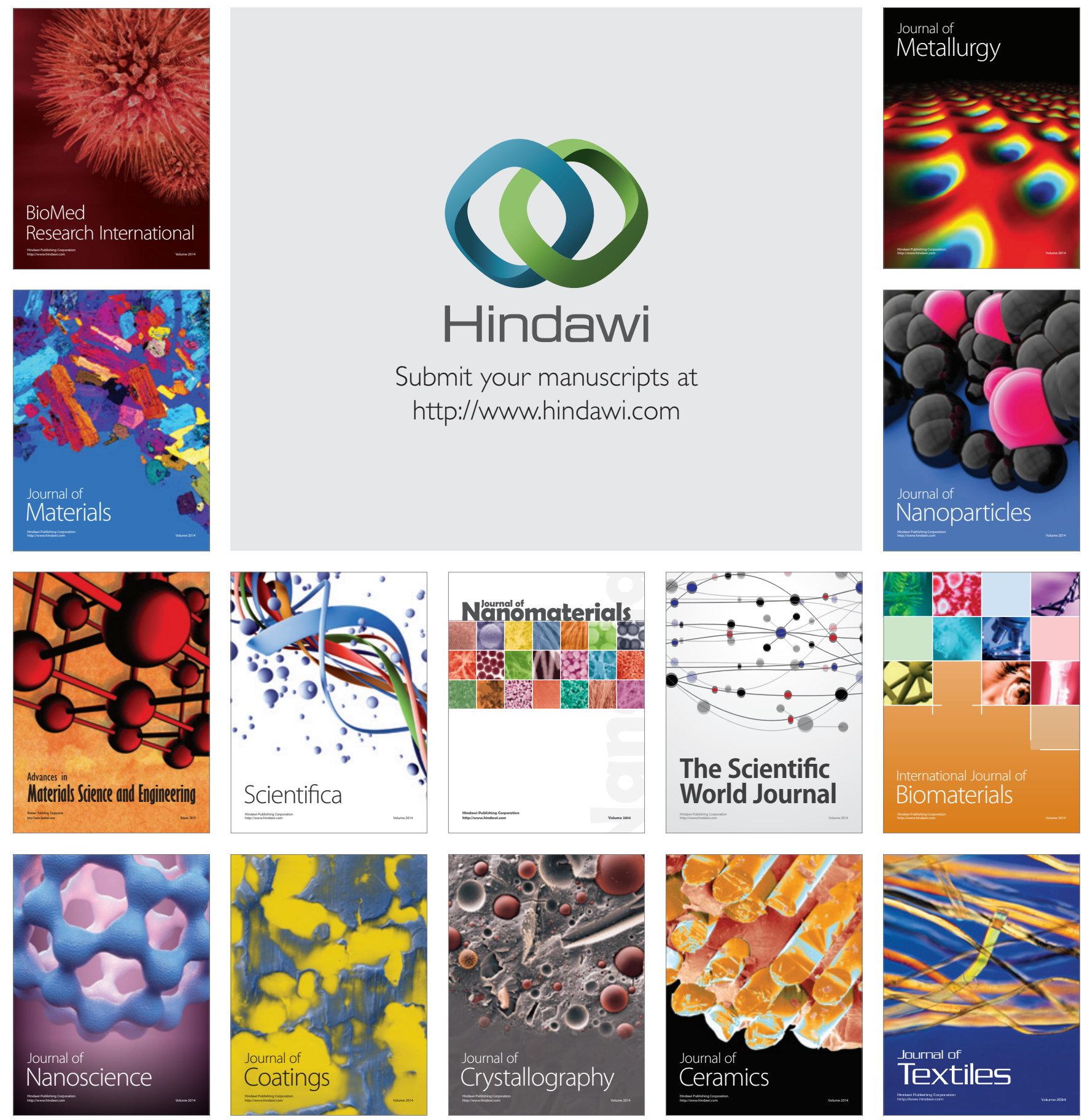